\title{
Synchronous Compensators: Models Verified by Tests of Automatic Voltage Regulator, Reactive Power Control, and Voltage Joint Control
}

\author{
Jorge Luis Agüero, Senior Member, IEEE, Patricia Liliana Arnera, Senior Member, IEEE, \\ Raúl E. Bianchi Lastra, Senior Member, IEEE, and Mario César Beroqui
}

\begin{abstract}
This paper presents models verified by tests of the excitation control systems (ECSs) of six large synchronous compensators (SCs) rated +125/-120 MVAr.

These equipments for grid voltage control are placed in the substation Ezeiza of $500 \mathrm{kV}$ belonging to the Interconnected Argentine System (SADI in Spanish). The substation Ezeiza is located in the SADI load center.

Each SC has an ECS integrated by an automatic voltage regulator (AVR) with several limiters and a reactive power control (RPC). ECSs are governed by a single voltage joint control (VJC) to control the voltage at a 500-kV bus bar.

The ECS is UNITROL $F$ from $A B B$ and, the $V J C$ is implemented in a programmable logic controller (PLC).

The AVR, RPC, and VJC models are presented. These models were predefined with information furnished by the manufacturer.

Then, these models were validated by tests. Test records and their simulations with the proposed model are also presented.

Described models have been incorporated to the database of dynamic models used for stability studies in the SADI.
\end{abstract}

Index Terms-Control system, excitation systems, limiters, modeling, reactive power control (RPC), testing, voltage control.

\section{INTRODUCTION}

$\mathbf{S}$ EVERAL tests were made at synchronous compensators (SCs) plant during the commissioning of a new excitation control systems (ECSs). These tests were made to verify all the models involved and their adjustments.

The SCs are a 3901/01/660 type from General Electric, rated $13.8 \mathrm{kV}$ and $+125 /-120$ MVAr. Each SC has a shaft mounted exciter 3901/01/340 type from General Electric used as a driving motor for startup.

Fig. 1 shows the substation Ezeiza where the SCs are emplaced. Each pair of SCs is connected to one of the two secondaries of a transformer rated 132/13.8/13.8 kV and 250/250/250 MVA with Yd1/Yd1 connection and with individual on-load tap. Each primary of these three transformers is connected to the tertiary of a transformer rated 500/220/132 kV and 800/800/350 MVA with $\mathrm{Yy} 0 / \mathrm{Yd} 1$ connection. The substation Ezeiza is interconnected to SADI grid through six 500-kV lines. Four of these six lines are $1600 \mathrm{~km}$ long, with series capacitor compensation,

Manuscript received September 15, 2004; revised December 23, 2004. This work was supported in part by TRANSNER SA. Paper no. TPWRS-005002004.

The authors are with the IITREE-LAT, Facultad de Ingeniería Universidad Nacional de La Plata, La Plata, Argentina (e-mail: iitree@iitree-unlp.org.ar).

Digital Object Identifier 10.1109/TPWRS.2006.879253

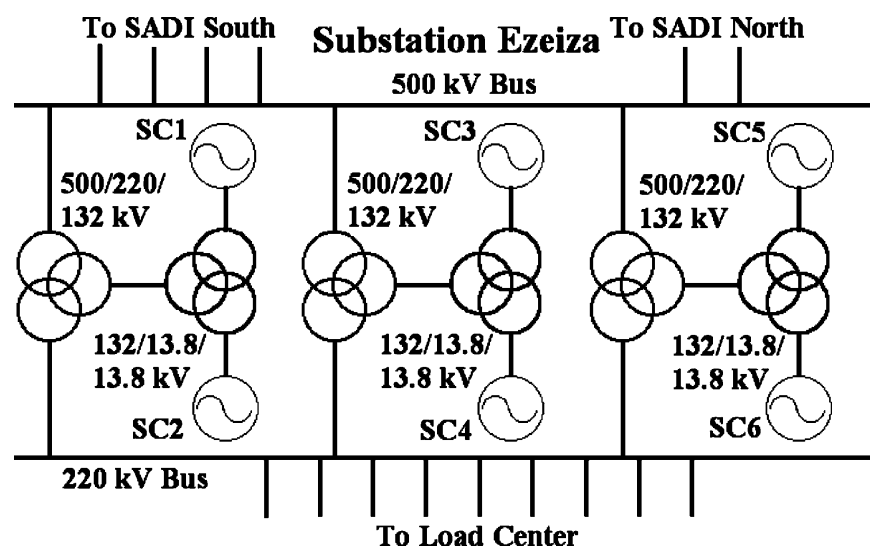

Fig. 1. Substation Ezeiza. SCs plant.

and carries power from Comahue electric area, located in the south SADI.

Comahue has several thermal and hydraulic power plants, with close to $10000 \mathrm{MW}$ of generation capability.

The last two of these six lines are connected to substation General Rodríguez, the connection point with the north SADI.

Substation Ezeiza is connected to the SADI load center (Buenos Aires city and surroundings) through several 220-kV lines. Then, the SCs plant control the $500-\mathrm{kV}$ voltage at a critical node of SADI grid.

Each SC has a new ECS integrated by an automatic voltage regulator (AVR) and a reactive power control (RPC). The AVR has the following limiters: one over excitation limiter (OEL), two under excitation limiters (UEL), and a $\mathrm{V} / \mathrm{Hz}$ limiter. The AVR also has compensation or droop to control a different voltage from the measured one.

The new voltage joint control (VJC) is implemented in a PLC.

Fig. 2 shows a simplified model of the six SCs at Ezeiza plant with the different control loop involved and their interconnection. Fig. 3 shows a simplified block diagram of one ECS shown in Fig. 2. This block is the same for each of the six SCs. The VJC set point (SP) for $500-\mathrm{kV}$ bus voltage is fixed by plant operator. The VJC block generates the set point (QT SP) for each of the six RPCs with the error between its set point (SP) and its controlled voltage $(500 \mathrm{kV})$. Then, steady-state control of $500-\mathrm{kV}$ bus voltage is obtained through the VJC operation as a tertiary closed loop control that changes simultaneously all the RPCs set points. 